\title{
Investigation of Electromagnetic Radiation Emitted from Mobile Base Stations in Khartoum State
}

\author{
Mohammed Idriss. Ahmed ${ }^{1}$, Mohammed Osman Sid Ahmed ${ }^{2}$, Hafiz F. AL Rahman ${ }^{3}$, \\ Isam Salih M. Musa ${ }^{3}$, Hajo Idriss ${ }^{4}$ \\ ${ }^{1}$ Department of Physics, Faculty of Science, Sudan University of science and Technology, Khartoum-Sudan \\ ${ }^{2}$ Sudan Atomic Energy Commission (SAEC), Khartoum - Sudan
}

\begin{abstract}
The fast development of mobile communication systems all over the world has caused the appearance of many hundreds of mobile telephone base stations in every municipality. Mobile base station set up has produced concerns about health and in some cases has resulted in litigation in court. Hence, radiological hazard assessments due to electromagnetic radiation emitted from 50 mobile base stations GSM900-GSM1800 were carried out. The measurement was performed at different distances and directions from 50 mobile base stations using Aaronia Hyper LOG $4040 \mathrm{X}$ instrument. The mean Power density $\left(0.00595 \mathrm{~W} / \mathrm{m}^{2}\right)$ and Power Ratio (-52 dBm) were determined and compared with International Commission on Non-Ionizing Radiation Protection (ICNIRP), World Health Organization allowable limits and different countries. On the other hand, the investigation highlights the importance of radiation monitoring of mobile phone antenna on a residential building.
\end{abstract}

Keyword: RF-EMF, Exposure, Residential building, Reference level

\section{Introduction}

According to the wide spread used radio frequency (RF) in general field and communication As wireless communication and use of non-ionizing radiation is increasing we urge establishing the value of exposure of it from environmental far - near field sources in everyday life. Electromagnetic spectrum is the distribution of electromagnetic radiation according to frequency such as radio frequency, Microwaves, infra-red, visible light, ultraviolet, $\mathrm{X}$ and $\gamma$ rays. With developing technology communication tools are became an indispensable part of our daily life. Most of those tools use the Radio Frequency Radiation (RFR) which is a part of the electromagnetic spectrum .TV and radio transmitters, base stations, radar systems, mobile phones, cordless phones, remote control systems are all RFR generators. Most of TV and radio stations are typically located in one antenna tower or a few towers that are close to each other. Mobile phone base stations also exist between TV and radio stations [1,2].

This increased use of mobile phone has led to increased deployment of base station. There are two sources of radiofrequency radiation exposure from the mobile telephone system: base station antenna and mobile phone or hand set .Exposure from base station antennas is continuous, irradiates the whole body and expose an entire community in different ways according to position and separation distance. The mobile phone system works as a network containing base stations within each cell, a base station can link with number of handsets. The mobile phone and base stations communication with each other, sharing a number of operation frequencies [3].

So antenna farms arise as complex areas in cities. Consequently, this situation has created unease feelings to the people that they may be affected by the radiation from those antennas. Public concern about potential health effects of human exposure to electromagnetic field from $\mathrm{RF}$ communication facilities are increases every day. These circumstances make the electromagnetic field (EMF) $[1,2]$. In the many documents the Basic restrictions are defined to protect the general public and workers from the adverse health effects of exposure to EMF by different commissions all around the world. However in some countries e.g. Switzerland or Italy exposure limits are determined by their own national authorities and more strict levels are valid [4].The main differences are that they integrate the exposure over time and have different criteria for the definition of damage and adverse health effects International Commission on Non-Ionizing Radiation Protection (ICNIRP) was launched as an independent commission [11,3].The main differences are that they integrate the exposure over time and have different criteria for the definition of damage and adverse health effects International Commission on NonIonizing Radiation Protection (ICNIRP) was launched as an independent commission [11, 3].American National Standards Institute (ANSI) operates as a part of Institute of Electrical and Electronics Engineers (IEEE) for safety standards on EMF exposures, World Health Organization (WHO) and Federal Communications Commission (FCC) are some of the other regulatory boards. Generally ICNIRP and ANSI/IEEE standards are most widely accepted all over the world $[13,4]$.These regulations occupied the standards for frequency range of the EMF exposure limits as recommended by ICINRP. The gross measurement of radiation from the antenna in the designated area compared with global measures $[13,3]$.

\section{Assessment of Exposure around Base Station}

Electromagnetic is combination of electric and magnetic field in the environment [21]. The electric field and magnetic field oscillate in time phase and direction is both mutually orthogonal and orthogonal direction of propagation. [5] 


\section{International Journal of Science and Research (IJSR) \\ ISSN (Online): 2319-7064 \\ Index Copernicus Value (2013): 6.14 | Impact Factor (2014): 5.611}

The power density is rate of the flow of electromagnetic energy per unit area used to measurement the amount of radiation at a given from transition antenna. [6]

$$
S=\frac{1}{2} \operatorname{Re}\lceil E \times H\rceil S=\frac{\left\lceil\mathrm{E}_{\mathrm{rms}}\right\rceil^{2}}{\mathrm{Z}_{\circ}}=\mathrm{Z}_{\circ}\left\lceil\mathrm{H}_{\mathrm{rms}}\right\rceil^{2}
$$

$\mathrm{E}, \mathrm{H}$ is electric and magnetic field intensity

$\mathrm{Z}=$ impendence of free space

The ratio between electric field strength and magnetic field strength is constant outside the reactive near field.In the free space the ratio is known as the intrinsic impendence of free space and takes the value 337 .consequently, equation 1 may be rewritten [5].

$$
S=\frac{E^{2}}{377}
$$

\section{Near-field power density evaluation}

In the near field region of antenna the energy is largely confined within a cylinder pattern of diameter D. The power density in the region can reach a maximum before it begins to decreased with distance and extent of the near field can be theoretically calculation by using the following equation: [7] [23]

$$
R=\frac{D^{2}}{4 \lambda}
$$

Where:

$\mathrm{R}=$ extent of near field, $\mathrm{D}=$ maximum dimension of antenna, $\lambda=$ wave length

The corresponded maximum value of power density is given by the following equation:

$$
S_{n f}=\frac{16 \eta P}{\pi D^{2}}
$$

Where

$S_{n f}=$ Maximum near field power density, $\eta=$ aperture efficiency

$\mathrm{P}=$ power field to antenna $\mathrm{D}=$ Antenna diameter

\section{Far-field power density evaluation}

The transition region extents from the end of near field and goes up to beginning of far field. Power density in the transition region decreases inversely with distance from antenna .To calculation the distance of the transition region we can use following equation:

$$
R_{f f}=\frac{0.6 D^{2}}{\lambda}
$$

$R_{f f}=$ Distance to beginning of far-field $\mathrm{D}=$ diameter, $\lambda=$ Wave length

The total power density can be given by the following equation:

$$
S=\frac{S_{n f} \cdot R_{n f}}{R}
$$

$\mathrm{S}=$ power density in transition region

$S_{n f}=$ Maximum power density for near field

$R_{n f}=$ extent of near field

$\mathrm{R}=$ Distance to point of interest.

If the total power density field into an antenna is known as well as the antenna gain to calculate the power density in the main beam by assuming an inverse law dependence upon distance at all distances from the antenna. The following equation is valid for power density in the far field use power density, $\mathbf{S}$, in this way [5].

$$
S=\frac{P_{\mathrm{rad}} \mathrm{G}}{4 \pi \mathrm{d}^{2}}
$$

Where $\mathrm{d}$ is the distance from the antenna $\boldsymbol{P}_{\text {rad }}$ is the total radiated power and $\mathbf{G}$ is antenna gain (in liner units).

The magnitude of far - field radiated by the base antenna system is determine by using the ray algorithm base on the geometrical optics method. Thus, the total electric field can be express as superposition of incidence and reflection compound. $[8,9]$.

$$
\begin{gathered}
\mathrm{E}_{\text {Total }}=\mathrm{E}_{\text {incidence }}+\mathrm{E}_{\text {reflection }} \\
\mathrm{E}_{\text {incidence }}=\mathrm{E}_{\circ}(\varnothing, \theta) \mathrm{e}^{-\mathrm{J} \beta \mathrm{R}} \\
\mathrm{E}_{\text {reflection }}=\rho \cdot\left(\varnothing^{-}, \theta^{-}\right) \mathrm{E}_{\circ} \frac{\left(\varnothing^{-}, \theta^{-}\right)}{\mathrm{R}^{-}} \mathrm{e}^{-\mathrm{J} \beta \mathrm{R}}
\end{gathered}
$$

Where:

$\rho=$ is the approximation reflection coefficient.

$E_{\circ}=$ is the magnitude of incidence wave.

$(\varnothing, \theta)=$ are spherical coordinate angles, $\beta$ is constant.

$\mathrm{R}=$ is distance from the base station.

\section{Types of exposure Zones}

Base on the reference level specified by ICNIRP, the compliance distance from base station antenna could be calculated with the help of equivalent Iso-Tropically radiation Power (EIRP watts) in the direction of the maximum gain of the antenna .hence, three types of exposure zones can be identified

\section{Compliance Zone}

Where potential exposure to EMF is below the applicable limits.

\section{Occupational Zone}

Where positional exposure of EMF is below the limits for occupational exposure but exceeds the limits for general public exposure. Here occupational refer to operational and maintenance staff.

\section{Exceedance Zone}

Where potentionial of EMF exceeds the limits for both occupational and general public exposure [10]

\section{Method Materials}

\section{Study area}

The State of Khartoum area $\left(22,142 \mathrm{~km}^{2}\right)$ lies between latitude $15-16 \mathrm{~N}$ and longitude 31.5 -34 East, located in the heart of Sudan at the confluence of the White Nile and the Blue Nile, where the two rivers unite to form the River Nile. The population census estimates the population of Khartoum state to be about 5, 274, 321 in year of 2008 . 


\section{International Journal of Science and Research (IJSR)

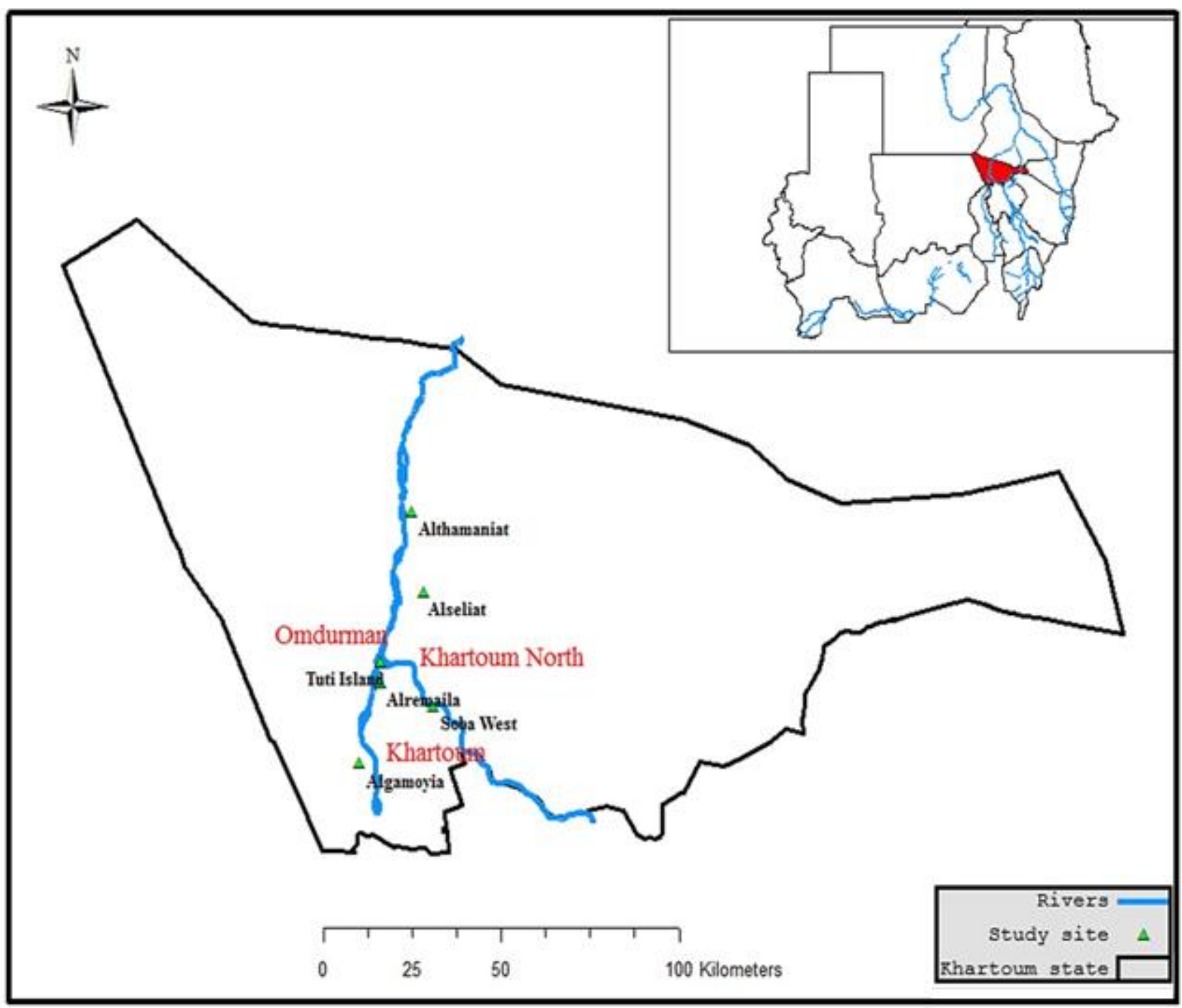

Figure 1: Map show the study area

\section{Measurement}

Aaronia Hyper LOG 4040 X" detectors have been used for electromagnetic radiation measurement. It has possible analysis and measurements within frequency range $(400 \mathrm{MHz}-4 \mathrm{GHz})$ Coverage of various mobile radio frequency ranges Suitable for field-strength and EMC measurements due to high precision Can be used in the lab and for open-field application. The area of was selected for the present study which demonstrates the use of various types of antennas and measurement at difference distance. In the survey, a GPS device was used to locate the coordinated of antennas. Measurements were performed up to $10-100 \mathrm{~m}$ far from the antenna. At each location, the type of antenna is determined using accompanied software (AaroniaLcs analyzer). The measuring devices (Hyper LOG 4040 X) are connected to a laptop for calibration purposes and to analyze the spectra. For each antenna the following data is obtained: exposure, electromagnetic electric field. In order to obtain more accurate values, many measurements are normally performed at every location. The following data is also recorded: power density, electric field and magnetic field. Figure shows display of spectrum and result of typical measurement. [12]

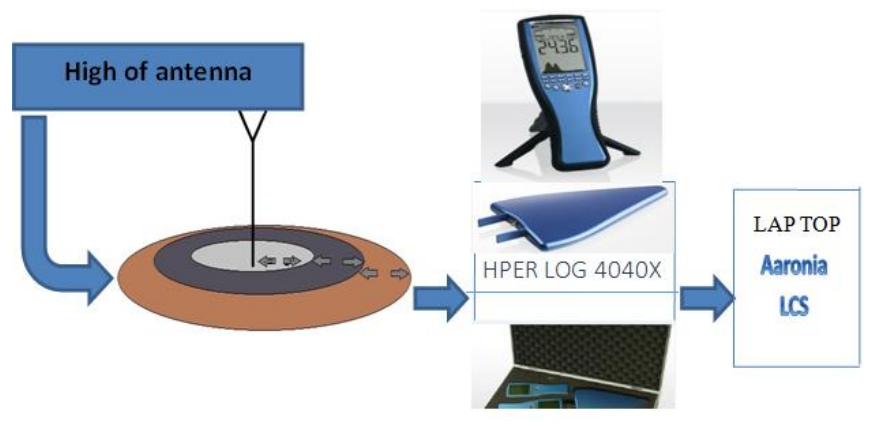

Figure 2: Schematic diagram show the principle of measurements

\section{Result and Discussion}

1. The calculation of power density radiation at distances ranging from $(1 \mathrm{~m}$ to $100 \mathrm{~m})$ from base station for different transmitting power and difference antennas and estimated the maximum power density from result from $(1$ to $10 \mathrm{~m})$ the mean was found value $\left(18.121 \mathrm{~W} / \mathrm{m}^{2}\right)$ near of antenna. After that that we take the value of power density from distance $(10,20,30,40,50,60,70$, 80, 90 and 100), the mean Power density (exposure) was $\left(0.00590 \mathrm{~W} / \mathrm{m}^{2}\right) 0.000590 \%$ at $50 \mathrm{~m}$ radius from antenna . According to the result the Sudan is no violation of power density (exposure). 


\section{International Journal of Science and Research (IJSR) \\ ISSN (Online): 2319-7064 \\ Index Copernicus Value (2013): 6.14 | Impact Factor (2014): 5.611}

Table 1: Power density with respect to distance and power ratio (1-10m)

\begin{tabular}{|c|c|c|c|c|}
\hline Distance $(m)$ & Latitude & Longitude & $\begin{array}{c}\text { Power Ratio } \\
(d B m)\end{array}$ & Power density $\left(\right.$ W/m $\left.^{2}\right)$ \\
\hline 1 & 32.53773 & 15.55633 & -74.1 & 18.121 \\
\hline 2 & 32.53703 & 15.55589 & -53.64 & 2.0254 \\
\hline 3 & 32.53645 & 15.54510 & -48.91 & 1.9273 \\
\hline 4 & 32.54601 & 15.54107 & -53 & 0.9562 \\
\hline 5 & 32.54097 & 15.54922 & -49.56 & 0.6640 \\
\hline 6 & 32.54089 & 15.55796 & -56.51 & 0.4206 \\
\hline 7 & 32.55329 & 15.53219 & -60.59 & 0.3090 \\
\hline 8 & 32.55246 & 15.54133 & -60.59 & 0.2342 \\
\hline 9 & 32.55151 & 15.54103 & -61.21 & 0.2064 \\
\hline 10 & 32.54597 & 15.54161 & -53 & 0.1867 \\
\hline
\end{tabular}

Table 2: Power density with respect to distance and power ratio (10-100m)

\begin{tabular}{|c|c|c|c|c|}
\hline $\begin{array}{c}\text { Distance } \\
(\mathrm{m})\end{array}$ & Latitude & Longitude & $\begin{array}{c}\text { Power } \\
\text { Ratio } \\
{[\mathrm{dBm}]}\end{array}$ & $\begin{array}{c}\text { Power } \\
\text { density } \\
(\mathrm{W} / \mathrm{m} 2)\end{array}$ \\
\hline 10 & 32.54597 & 15.54161 & -53 & 0.1867 \\
\hline 20 & 32.57156 & 15.53944 & -56 & 0.0479 \\
\hline 30 & 32.57634 & 15.53629 & -60.56 & 0.0196 \\
\hline 40 & 32.57512 & 15.53620 & -66.5 & 0.0193 \\
\hline 50 & 32.55320 & 15.53055 & -64.66 & 0.0059 \\
\hline 60 & 32.55011 & 15.52783 & -63.18 & 0.0049 \\
\hline 70 & 32.55748 & 15.52602 & -67.45 & 0.0041 \\
\hline 80 & 32.56577 & 15.52702 & -39.21 & 0.0039 \\
\hline 90 & 32.57189 & 15.53456 & -47.66 & 0.0022 \\
\hline 100 & 32.53402 & 15.53322 & -44.8 & 0.0013 \\
\hline
\end{tabular}

2. Figure 1, 2 the represented the power density dramatically decline when we far for the antennas and the power density in the result is proportional to the square of the distance from antenna. If, for example the distance from antenna increased by two times, the power density increasing four times.

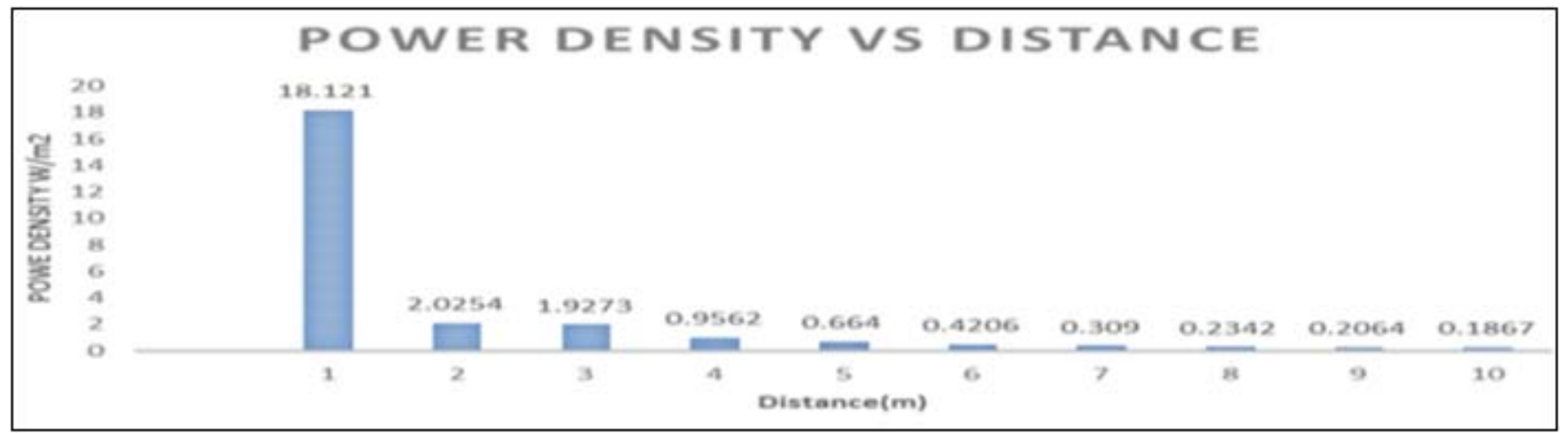

Figure 1: Power Density Virus Distance from (1-10 m)

respectively. Represented about $0.08 \%, 0.000590 \%$ of total value of guideline there are no risk of electromagnetic

3. In Figures 3,4 show the relation between the Electric field and power density (exposure) virus International guideline levels, The Electric field and Power density in the Sudan were found $(0.826 \mathrm{~V} / \mathrm{m}), \quad(0.00590 \mathrm{~W} / \mathrm{m} 2)$ radiation in Sudan also said the Sudan is safety area of electric field and power density. 


\section{International Journal of Science and Research (IJSR) \\ ISSN (Online): 2319-7064}

Index Copernicus Value (2013): 6.14 | Impact Factor (2014): 5.611

\section{Power Density Vs Disatnce}

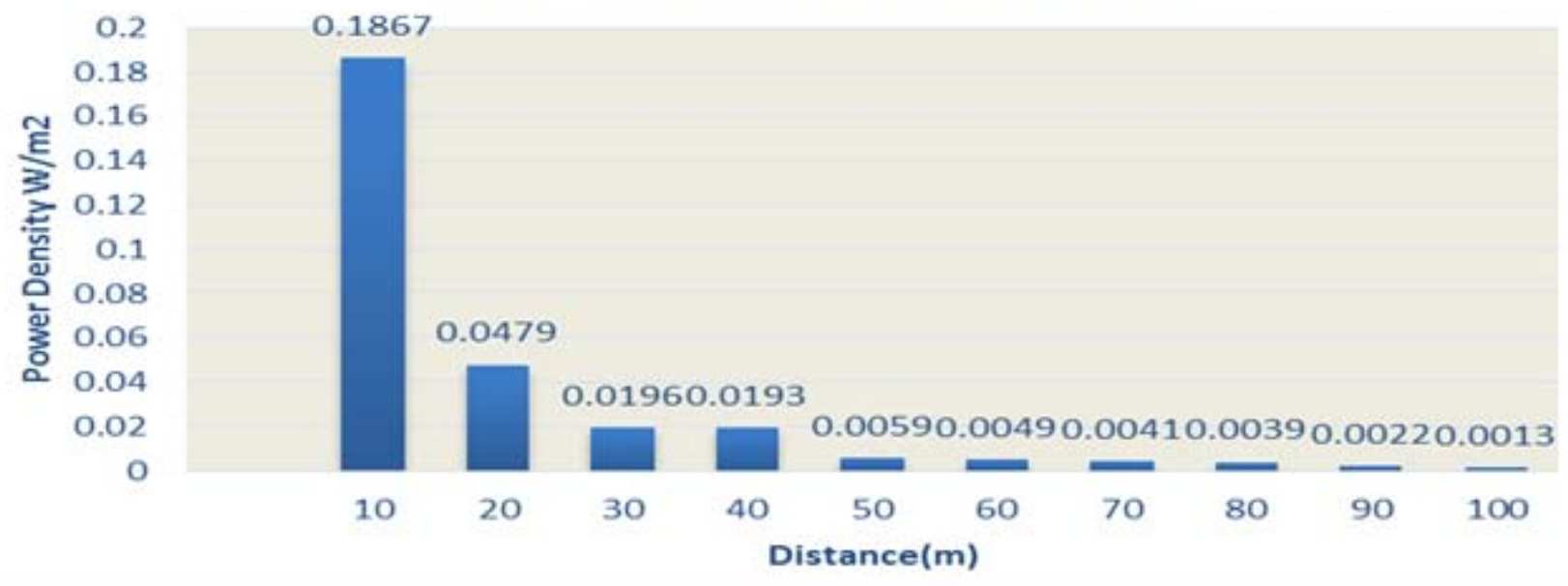

Figure 2: Power Density Virus Distance from (10-100m)

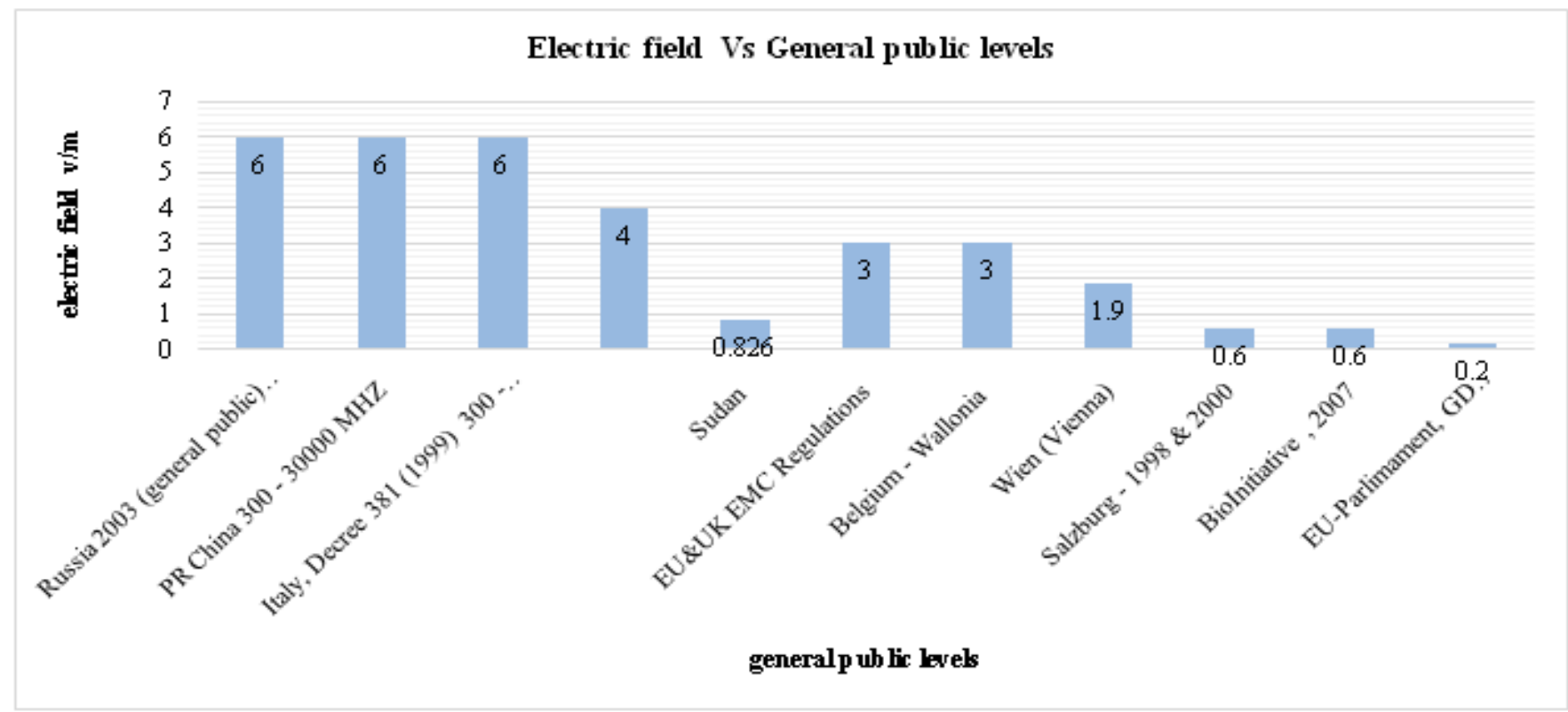

Figure 3: Electric field Vs General public levels

Table 3: General Public levels and Electric Field

\begin{tabular}{|c|c|}
\hline General Public Levels (Frequency) & $\begin{array}{c}\text { E field } \\
\text { V/m }\end{array}$ \\
\hline Russia 2003 (general public) 300 - 30000 MHZ & 6 \\
\hline PR China 300 - 30000 MHZ & 6 \\
\hline Italy, Decree 381 (1999) 300 - 30000 & 6 \\
\hline Swiss Ordinance ORNI, rms values 900 - 1800 & 4 \\
\hline Sudan & 0.826 \\
\hline EU\&UK EMC Regulations & 3 \\
\hline Belgium - Wallonia & 3 \\
\hline Wien (Vienna) & 1.9 \\
\hline Salzburg - 1998 \& 2000 & 0.6 \\
\hline BioInitiative, 2007 & 0.6 \\
\hline EU-Parlimament, GD Wissenschaft, STOA & 0.2 \\
\hline GSM(2001) & \\
\hline
\end{tabular}

Table 4: General Public levels and power density

\begin{tabular}{|c|c|}
\hline General Public levels(Frequency) & $\begin{array}{c}\text { Power density } \\
\text { (Exposure) } \\
\mathrm{W} / \mathrm{m} 2\end{array}$ \\
\hline Russia 2003(general Public & 0.1 \\
\hline Rf china(200-3000MHz) & 0.1 \\
\hline Italy, Decree381(1999)(300-3000MHz) & 0.1 \\
\hline ICNIRP2010(400-2100MHz) & 10 \\
\hline Belgium-Wallonia(900-2100) & 0.024 \\
\hline Wien(Vienna) & 0.01 \\
\hline Sudan & 0.00590 \\
\hline BioInitiative, 2007 & 0.001 \\
\hline EU-Parliament, GDWissenschaft, STOA & 0.0001 \\
\hline GSM(2001) &
\end{tabular}


International Journal of Science and Research (IJSR)

ISSN (Online): 2319-7064

Index Copernicus Value (2013): 6.14 | Impact Factor (2014): 5.611

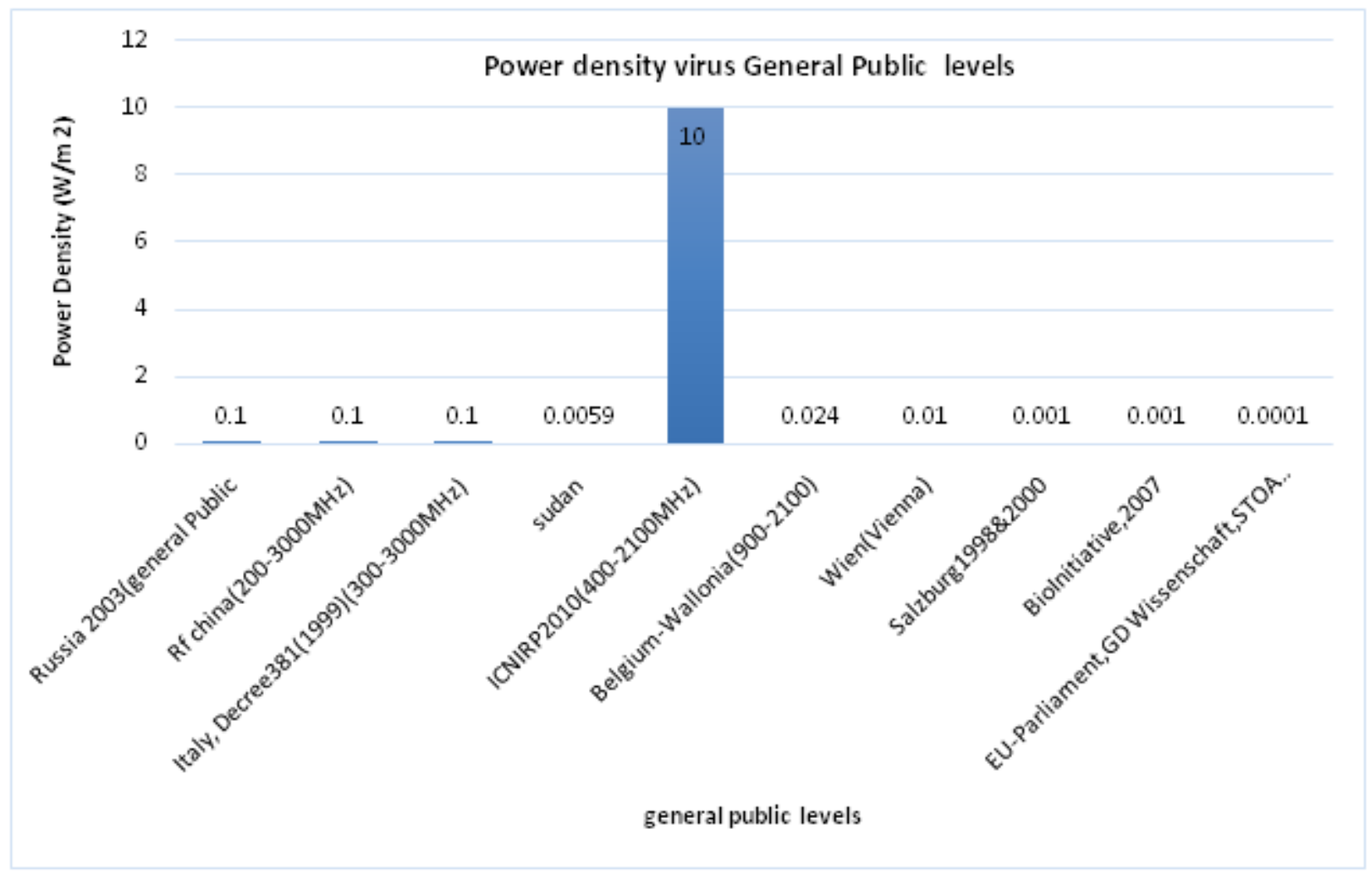

Figure 4: Power density Virus General Public Level

\section{Conclusion}

In this paper, the power density level over distance from base stations are investigated, the results of the calculations are summarized as follows:-

1) The permitted levels are exceeded within a distance of $10 \mathrm{~m}$ directly in front of the antennas radiating surface, this is, in many case within the areas where people living around the base stations and; therefore, the expose to radio wave .Compliance distance in other directions, such as above and below the antenna, would be smaller. During measurement the maximum power density levels from the antennas never exceed the reference level. Power density was in the range $\left(0 \mathrm{~W} / \mathrm{m}^{2}\right.$ $0.00590 \mathrm{~W} / \mathrm{m}^{2}$ ) at distance $50 \mathrm{~m}$

2) In Sudan, the use increasing used cellar mobile phone dramatically, we establish the central laboratory to perform basic studies of non- ionizing radiation and effects of RF of any countries in African and other studies is necessary.

3) Obviously, the guideline for EMF radiations from BTS and mobile handset in Sudan are very low when compared to developed countries like USA, Canada, Japan, Russia, China and Australia. In addition the Sudan are very stringent power density when it the adopted by some international organizations like WHO, HPS, SRSA, NIPH.

4) In order to lower exposure for people living nearby the antennas are suggested here. These include setting minimum distance of $30-40 \mathrm{~m}$ from the nearest house and $>50 \mathrm{~m}$ for safety buildings. Such as the schools, Hospitals.

\section{Acknowledgments}

This work is supported by Sudan university science \& Technology and Sudan atomic energy commission (SAEC).

\section{References}

[1] T. G. Cooper, S. M Mann, M Khalid and R. P. Blockwell; "Public Exposure to Radio Waves near GSM Microcll and Picocell Base Station “, J. Radiol. Port. 26, 199-211, 2006.

[2] Md. R. Islam, O. O. Khlifa, L. Ali, A. Azil, M. Zulkarnain; "Radiation Measurement from Mobile Base Stations at a University Campus in Malaysia", American Journal of applied Science 2(4), 1781-1784, 2006.

[3] U. Bergqvist, G. Friedrich, Y. Hamnerius, L. Martens G. Neubauer, G. Thuroczy, E. Vogel and J. Wiart, "Mobile Telecommunication Base Stations Exposure of Electromagnetic Field", Report of a short Term Mission on Base Statation Exposure with COST244bits, 2001, pp. 1-77.

[4] U. Bergqvist, G. Friedrich, Y. Hamnerius, L. Martens G. Neubauer, G. Thuroczy, E. Vogel and J. Wiart, "Mobile Telecommunication Base Stataions Exposure of Electromagnetic Field", Report of a short Term Mission on Base Statation Exposure with COST244bits, 2001, pp. 1-77.

[5] Ahmed Y. Tesneli, N. Berrna Tesneli, Bahakanberoglu, "Measurement of electromagnetic radiation in an Urban environment".

[6] John D. Kraus, Ronald J. Marhefka,"Antennas For All Applications", 2rd Edition, McGraw- Hill 1997, pp. 175. 
[7] K. Siwiak "Radio wave propagation and Antennas for person Communication" 3rd Edition, Artech House, Boston, London, 2007.

[8] Federal Communications Commission Office of Engineering\& Technology:" Evaluation Compliance with FCC Guidelines for Human Exposure to Radiofrequency Field" OET Bulletin 65 Edition 1-97.

[9] P. Bernardi, M. Cavagnaro, S. Pisa, E. Piazzi, "Human Exposure in the Vicinity of Radio Base Satiation Antennas", 4th European Symposium on Electromagnetic Compatibility (EMC Europe 200), Brugge, Belgium, September11-15, 2000, PP. 187-192.

[10] P. Bernardi, M. Cavagnaro, S. Pisa, E. Piuzzi, "Human Exposure to Radio Base Satiation Antennas in Urban Enlivenment" IEEE Transaction MTT, Vol 48, No. 11, November2000, PP. 1996-2003.

[11] Mahanagar Doorsanchar Bhawan and Jawahar Lal Nehru Marg, "Effects of Electromagnetic Field Radiation from Mobile Towers and Handset" 30th July, 2014, p. p1-39.

[12] Recommended 1998 of International Commission of Non-Ionizing Radiation Protection ICNRP. http://www. Aaronia" www. Aaronia. de.

[13]ICNIRP Guidelines for limiting Exposure to Time Varying, Magnetic, and Electromagnetic field sc up 300GHZ, Heath Physics, Vol 74 No 4, 1998 PP. 494522.

\section{Author Profile}

Mr. Mohammed Idriss Ahmed is a $\mathrm{PhD}$ student in Sudan University of science and Technology, Khartoum-Sudan. He received an MSc degree in General Physics from Khartoum University -Sudan in 2011, and BSc degree of Physics in same university 2007. His research area of interest Nonionizing Radiation, Electromagnetic Wave and communication.

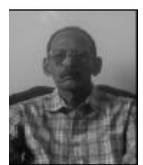

Prof. Mohamed Osman Sid - Ahmed received Ph. D degree in Solar Energy from University of Reading (UK) in 1981, an MSc degree in Meteorology in 1970, B. Sc degree in Physics in 1967 from the same university Reading- U.K. He worked in department of Meteorology Khartoum-Sudan from1970-1975. From 1975-1986 he was Researcher in the Energy Research Institute and National Council for research Khartoum-Sudan. From 1986 -1990, he was an associate Professor and Head of the Applied Physics departmentUniversity Gezira-Sudan. From 1990-1994, he was an associate Professor and Head of Wind Energy Department, National Centre for Research, Khartoum-Sudan. From 19941996, he was, Dean of Faculty of Education, University of ElFashir-Sudan. From 1997-2003 he was, Head of physics Department, Hail T. College, Saudi Arabia.From2003-2005 he was, Head of physics Department- Sudan Univ. of Science and Technology .He is currently a professor of physics, Physics Dept., Sudan Univ. of Science and Technology, Khartoum-Sudan. His research interests are radiative heat transfer and organic solar cells, Renewable Energy and non -ionizing radiation. 